\title{
TÁC ĐỘNG CỦA MỞ RộNG ĐÔ THỊ ĐẾN DI SẢN VĂN HÓA: NGHIÊN CÚU Ở KHU VỰC QUẦN THỂ DI TÍCH HUẾ
}

\author{
PHẠM VĂN MẠNH(1), NGUYẼ̃N NGỌC THẠCH(1), BÙI QUANG THÀNH(1), \\ PHẠM VŨ ĐÔNG ${ }^{(1)}$, PHẠM MINH HẢI ${ }^{(2)}$ \\ () Truoòng Đại học Khoa học Tự nhiên, Đại học quốc gia Hà Nội \\ (2) Viện Khoa học Đo đạc và Bản đồ, Bộ Tài nguyên và Môi truờng
}

\section{Tóm tắt:}

Nhũng biến động đô thị tốc độ nhanh và quy mô rộng trong nhũng thập kỷ gần đây đã gây ra rất nhiều thách thức trong công tác bảo tồn và quy hoạch sủ dụng đất, đặc biệt là công tác bảo tồn di tích lịch sủ. Tốc độ phát triểnđặt ra một thách thức cho các nhà quy hoạch đô thị, việc mở rộng ranh giới thành phố thuờng xuyên vượt quá quy hoạch. Điều này dẫn đến nhũng thách thức hơn nũa cho các nhà quy hoạch đô thị, cu thể là (i) cơ sở dũ liệu quy hoạch thường bị lỗi thời và (ii) các quá trình, mô hình tăng trương đô thị không có kế hoạch không được tính toán một cách hợp lý. Bài viêt này trình bày một cách tiếp cận để giải quyết những thách thức này bằng cách sư dụng dũ liệu viễn thám đa thời gian để nghiên cứu sụ thay đổi lớp phủ/sủ dụng đất trong gần nửa thế kỷ (1968-2016) bằng cách sử dụng dũ liệu vệ tinh SPOT và bản đồ địa hình tù NIMA do thu viện truòng Đại hoc Texas công bố. Một phân tích chi tiết về mở rộng không gian đô thị được định lương bằng các chỉ số đô thị hóa khác nhau. Kết quả chỉ ra rằng quá trình mở rộng đô thị đã mang lại nhũng thay đổi lớn về sử dụng đất và tăng trương đô thị, dẫn đến nhũng tác động đáng kể đến không gian cảnh quan của các di tích. Các phát hiện tiếp tục cho thấy sụ suy giảm về đất nông nghiệp và không gian xanh kéo dài trong suốt 48 năm. Kết quả không chỉ xác nhận khả năng úng dụng và hiệu quả của phưong pháp tích hợp giữa viễn thám và đo luờng mà còn cho thấy các đặc điểm đáng chú ý về thời gian của thay đổi sử dụng đất và động lực mở rộng đô thị trong các khoảng thời gian khác nhau (1968-1995, 1995-2000, 2000-2005, 2005-2011, và 2011-2016).

\section{1. Đặt vấn đề}

Biến đổi lớp phủ/sử dụng đất gây ra do quá trình đô thị hóa không chỉ ảnh hưởng đến môi trường mà còn trở thành yếu tố quan trọng trong các vấn đề kinh tế-xã hội [8]. Đây là trạng thái tự nhiên của bề mặt đất chịu tác động của các đặc điểm tự nhiên lẫn các hoạt động nhân tạo ở quy mô không gian và thời gian khác nhau. Quá trình đô thị hóa thể hiện trong việc mở rộng phạm vi không gian diện tích xây dựng (nhà ở, khu công nghiệp, cơ sở hạ tầng,...) trong kết nối trực tiếp với khu vực đô thị [4], với những thay đổi đột ngột của đất nông nghiệp, giảm không gian xanh, gia tăng sự phân mảnh của đất, giảm chất lượng không khí và thay đổi hệ thống thoát nước tự nhiên [1]. Đáng chú ý hơn, tốc độ đô thị hóa hiện nay diễn ra nhanh chóng đã phá vỡ quy hoạch không gian tại nhiều thành phố, đe dọa đến tuổi thọ và sự an toàn của di sản văn hóa. Một số nhà nghiên cứu đồng ý rằng việc mở rộng đô thị có thể là một trong những mối đe dọa quan trọng nhất đối với khu vực di sản văn hóa và do đó cần có các biện pháp thích hợp nhằm ngăn ngừa sự phá huỷ đó khi không có tài liệu hoặc chưa được điều tra đầy đủ $[2,6]$. Do đó, một đánh giá chính xác về tình trạng đô thị hóa hiện tại và các quá trình chính thức và không chính thức dẫn đến mở rộng đô thị là cần thiết để đảm bảo mở rộng đô thị bền vững và giảm thiểu tác động xấu đến cảnh quan và môi trường xung quanh di sản văn hóa.

Sự phát triển của GIS-Viễn thám đã có thể 
hiện thực hóa các tác động trong không gian lãnh thổ. Công nghệ viễn thám có tiềm năng lớn và là công cụ quan trọng để điều tra, dự đoán và dự báo sự thay đổi của sử dụng đất và sự cố thông qua việc phát triển các mô hình dựa trên GIS và các công cụ hỗ trợ ra quyết định đã được cải thiện đáng $[1,9,12,14]$. Ảnh vệ tinh có thể cung cấp một cách nhanh chóng để giám sát các động lực không gian của việc mở rộng đô thị. Phân tích mở rộng đô thị lịch sử có thể tiết lộ các động lực, quá trình và loại mở rộng đô thị, giúp quản lý phát triển đô thị một cách hiệu quả [5]. Trên cơ sở dữ liệu giám sát với hình ảnh vệ tinh đa thời gian, quá trình đô thị hóa thường được tiến hành phân tích định lượng các lớp thông tin về đối tượng lớp phủ/sử dụng đất. Quy mô và tốc độ đô thị hóa được coi là hai chỉ số đại diện cho tình trạng mở rộng của đô thị [7]. Các chỉ số này mô tả các đặc điểm của các mẫu động trong không gian. Trong các nghiên cứu trên, bốn chỉ số chỉ báo mức độ tăng trưởng của quá trình đô thị hóa bao gồm chỉ số Tăng hàng năm; Tỷ lệ mở rộng hàng năm; Tỷ lệ phần trăm đất đô thị; và chỉ số Cơ sở hạ tầng xanh đô thị. Các chỉ số này cung cấp thông tin định lượng có liên quan để mô tả sự thay đổi ở các khu vực đô thị.

Nghiên cứu này được tiến hành dựa trên dữ liệu bản đồ-viễn thám thu thập được từ năm 1968 đến 2016, do đó bao gồm thời kỳ phát triển đô thị nhanh chóng ở Quần thể di tích Huế. Mục tiêu của nghiên cứu là định lượng những thay đổi về không gian trong lớp phủ/sử dụng đất được thúc đẩy bởi sự mở rộng đô thị giữa thời kỳ 1968-1995; 1995-2000; 2000-2005; 2005-2011; và 2011-2016. Các kết quả từ nghiên cứu cung cấp cái nhìn chi tiết về quá trình đô thị hóa tại Quần thể di tích Huế đã và đang diễn ra; chỉ ra nhưng vấn đề cần quản lý và giám sát để thúc đẩy tăng trưởng thân thiện với môi trường; từ các dữ liệu ảnh vệ tinh có độ phân giải cao có thể phù hợp cho phân tích quá trình mở rộng đô thị, cũng như chỉ ra tác động đến môi trường từ phân tích các chỉ số đô thị hóa, kết hợp với phương pháp định lượng tăng trưởng đô thị và mối quan hệ đối với môi trường tự nhiên.

\section{Dũ̃ liệu và phương pháp nghiên cứu}

\subsection{Khu vục nghiên cú́u}

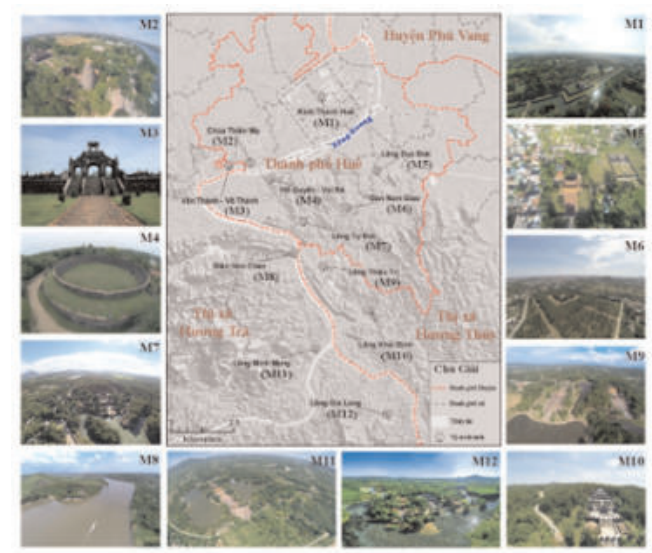

Hình 1: Khu vực Quần thể di tích Huế, thị trấn Hương Trà và Huoong Thủy của tỉnh Thù̀a Thiên - Huế; và các địa điểm của 12 di tích lịch sủ chinh

Ở Việt Nam Quần thể di tích Huế là hình ảnh thu nhỏ của những thành tựu về văn hoá, kiến trúc, lịch sử, là minh chứng cho quyền lực ở đỉnh cao của thời kỳ phong kiến cuối cùng của Việt Nam đầu thế kỷ 19. Để nghiên cứu tác động của quá trình đô thị hóa gần đây từ đợt ảnh hưởng chiến tranh quân sự cuối cùng, đã chọn năm 1968 làm điểm khởi đầu của thời kỳ nghiên cứu. Các di tích này đã chịu sức ép từ hoạt động định cư, sinh sống của dân cư ở khu vực lân cận. Mặc dù Quần thể di tích Huế đã được xếp hạng trong danh sách di sản thế giới của UNESCO từ 1993, nhưng những nỗ lực để bảo tồn sự thống nhất của của di tích đã gặp rất nhiều khó khăn do chiến lược ưu tiên phát triển kinh tế xã hội. Vì lý do này việc duy trì các đặc trưng văn hóa cơ bản và cảnh quan tự nhiên xung quanh di tích và các điều kiện sinh thái đã trở thành vấn đề quan trọng.

Để giám sát sự chuyển đổi mang tính động này, đã chiết tách thông tin liên quan từ dữ liệu viễn thám đa thời gian và áp dụng phương pháp GIS. Nghiên cứu này đã sử dụng dữ liệu viễn thám và dữ liệu phụ trợ trong khoảng thời gian gần nửa thế kỷ 1968-2016 để phân loại lớp phủ/sử dụng đất, bao gồm khu vực xây dựng công trình mật độ cao (HDB), khu vực xây dựng 
mật độ thấp (LDB), đất nông nghiệp (AGR), thực thể nước (WT), rừng (FR), khu vực phủ xanh (UGS), đất trống (BS), và nghĩa trang (CEM).

\subsubsection{Xư lý và phân loại dựa trên đối tượng}

Quá trình tiền xủ lý ảnh vệ tinh và dũ liệu phu trơ

Để xác định xu hướng của quá trình đô thị hóa trong khu vực nghiên cứu, dữ liệu không gian chính được sử dụng trong nghiên cứu này bao gồm bản đồ địa hình chi tiết năm 1968 từ Cục Bản đồ quốc gia (NIMA), mô hình số độ cao $(2,5 \mathrm{~m})$ cùng với các ảnh hàng không, ảnh vệ tinh độ phân giải cao năm 1995, 2000 (SPOT3$17 / 3$ và $6 / 11$, ảnh toàn sắc độ phân giải $10 \mathrm{~m}$ và ảnh đa phổ độ phân giải 20m); 2005, 2011 (SPOT5-16/02 và 29/05, ảnh toàn sắc độ phân giải $10 \mathrm{~m}$, ảnh đa phổ độ phân giải $2,5 \mathrm{~m}$ ); và năm 2016 (SPOT7-20/9, ảnh toàn sắc độ phân giải $6 \mathrm{~m}$, ảnh đa phổ độ phân giải $1,5 \mathrm{~m})$. Khu vực nghiên cứu có độ che phủ mây dưới $10 \%$. Các ảnh SPOT đa phổ đều được hiệu chỉnh, và loại bỏ ảnh hưởng của khí quyển bằng phương pháp ATCOR (Atmospheric Correction) được tích hợp trong phần mềm PCI Geomatics 2018 (Trial mode). Quá trình xử lý bao gồm ba phần: (i) Phản xạ trên cùng của khí quyển (TOA); (ii) Loại bỏ khói mù và mây mờ; (iii) Hiệu chỉnh khi quyển về phản xạ bề mặt [10]. Những ảnh vệ tinh được quy chiếu về hệ tọa độ WGS84/UTM$48 \mathrm{~N}$ cùng với các điểm khống chế mặt đất, hiệu chỉnh trực giao bằng mô hình số độ cao để đảm bảo độ chính xác nắn chỉnh hình học đạt sai số +-0.5 pixel. Dữ liệu tiếp tục được hiệu chỉnh phổ bằng các kỹ thuật tăng cường ảnh để làm giảm sự khác biệt về mùa trên các ảnh khác nhau. Cuối cùng các ảnh được xử lý tái chia mẫu ảnh sao cho có cùng độ phân giải không gian $2,5 \mathrm{~m}$ nhằm chuẩn bị cho bước chiết tách thông tin lớp phủ/sử dụng đất với đạt độ chính xác cao.

Bản đồ địa hình năm 1968 của khu vực nghiên cứu có tỷ lệ $1: 50.000$, đối với khu vực kinh thành Huế có tỷ lệ 1:12.500 được tải về từ NIMA do thư viện trường Đại học Texas công bố. Các tư liệu này được số hóa, biên tập và sử dụng để thu thập thông tin lớp phủ/sử dụng đất cùng với dữ liệu GIS bổ sung từ Cục Đo đạc bản đồ và thông tin địa lý của Việt Nam (2017). Các bản đồ này bao gồm nhiều thông tin cần thiết, gồm có địa hình và các thông tin bề mặt đất khác tương đương với các lớp trong lớp phủ/sử dụng đất.

\section{Phân loại dựa trên đối tượng}

Với sự thành công của phân loại có giám sát dựa trên đối tượng (Object-based) với các giải pháp không gian ngày càng tăng và trở nên thuận lợi so với phương pháp tiệp cận dựa trên điểm ảnh (Pixel-based) truyền thống, đặc biệt về phương diện phân biệt đặc điểm của đô thị, phương pháp phân loại dựa trên đối tượng đã cho thấy khả năng phân loại tốt hơn [11, 13]. Tuy nhiên, không có một quy tắc nào để làm theo hay một tiêu chí nào tuyệt đối để phân đoạn ảnh là tốt hay không tốt. Phân đoạn ảnh được thực hiện dựa trên việc lựa chọn các trọng số về hình dạng (shape), độ chặt (compactness), tham số tỷ lệ (scale parameter) là một thông số quan trọng có tác động trực tiếp tới kích thước của mỗi đối tượng trên ảnh. Tùy thuộc vào độ phân giải không gian của các loại ảnh vệ tinh khác nhau mà các tham số này thay đổi. Nghiên cứu này, đã lựa chọn kết quả phân đoạn ảnh với các tham số scale: 15 , shape: 0,8 và compactness: 0,5 .

\section{Chỉnh sưa hậu phân loại}

Lựa chọn các mẫu kiểm tra được giả định rằng tất cả các đối tượng trong một lớp được bao phủ một mức độ thích hợp và phân bố đều trên toàn khu vực nghiên cứu. Đánh giá này được thực hiện trên phân loại cuối cùng sau khi thực hiện sàng lọc sau phân loại, để sửa một số nhầm lẫn giữa lớp đất nông nghiệp (AGR) với LDB có thể được loại bỏ cũng như sự nhầm lẫn giữa các lớp AGR (trống), khu vực xây dựng mật độ thấp (LDB) và khu vực xây dựng mật độ cao (HDB) ở xa khu vực trung tâm của thành phố, loại bỏ các mảnh pixel nhỏ không mong muốn hoặc các pixel đơn lẻ sai cũng được lọc ra. Nghiên cứu sử dụng độ chính xác tổng thể Overall accuracy 
(OA), và hệ số thống kê Kappa (Kappa) để đánh giá độ chính xác kết quả phân loại[3].

\subsubsection{Các chỉ số đô thị hóa}

Các chỉ số đô thị hóa (UI) là một thước đo biểu thị đơn giản của sự phát triển đô thị, chỉ số đô thị hóa đã được tạo ra để lượng hóa sự thay đổi cảnh quan từ nhiều ảnh viễn thám. Các chỉ số này mô tả đặc tính của các mẫu dạng động trong không gian. Nghiên cứu này sử dụng 4 công thức tính đô thị hóa: Chỉ số Tăng hàng năm AI (công thức 1); Chỉ số mở rộng hàng năm AER (công thức 2); Chỉ số phần trăm đất đô thị ULP (công thức 3); và Chỉ số cơ sở hạng tầng xanh đô thị UGI (công thức 4). Các chỉ số này cung cấp thông tin định lượng có liên quan để mô tả sự thay đổi ở các khu vực đô thị, được xác định bởi các công thức sau:

$$
\begin{aligned}
& \text { Chỉ số tăng hàng năm: } A I=\frac{\text { Area }_{(t 2)}-\text { Area }_{(t 1)}}{\operatorname{Area}_{(t 1)}} \times 100 \% \\
& \text { Chỉ số mở rộng hàng năm: } A E R=\left[\left(\frac{\text { Area }_{(t 2)}}{\text { Area }_{(t 1)}}\right)^{1 / n}-1\right] \times 100 \% \\
& \text { Chỉ số phần trăm đất đô thị: } U L P=\frac{\operatorname{Area}_{(t 2)}}{\operatorname{Area}_{(t o t a l)}} \times 100 \% \\
& \text { Chi số hạ tầng xanh đô thị: } U G I=\frac{U G S_{(t 2)}-U G S_{(t 1)}}{\left(H D B_{(t 2)}+L D B_{(t 2)}\right)-\left(H D B_{(t 1)}+L D B_{(t 1)}\right)} \times 100 \%
\end{aligned}
$$

Trong đó: $\mathrm{t}_{1}$ là thời gian năm trước; $\mathrm{t}_{2}$ là thời gian năm sau; n là số năm trong cả giai đoạn; Area $_{(\mathrm{t} 2)}$ là tổng diện tích đất đô thị trong năm sau; Area $_{(\mathrm{t} 1)}$ là tổng diện tích đất đô thị trong năm trước; Area ${ }_{(\text {total }}$ là tổng diện tích đất; HDB là diện tích đất xây dựng mật độ cao, LDB là diện tích đất xây dựng mật độ thấp; UGS là diện tích khu vực phủ xanh.

\section{Kết quả nghiên cứu và thảo luận}

\section{1. Độ chính xác và kết quả phân loại}

Kết quả phân loại các đối tượng lớp phủ/sử dụng đất bao gồm: khu vực xây dựng mật độ cao (HDB), khu vực xây dựng mật độ thấp (LDB), đất nông nghiệp (AGR), thực thể nước (WT), rừng $(\mathrm{FR})$, khu vực phủ xanh (UGS), nghĩa trang $(\mathrm{CEM})$ và đất trống $(\mathrm{BS})$. Kết quả phân loại năm 1968 được số hóa (từ bản đồ tham chiếu NIMA thành lập năm 1968) cho phù hợp với các đối tượng lớp phủ/sử dụng đất của khu vực nghiên cứu. Độ chính xác kết quả phân loại tổng thể (OA) là 82,6\% (1968), 78,7\% (1995), 80,5\% (2000), 81,3\% (2005), 80,7\% (2011), và $82,8 \%$ (2016) trong khi hệ số Kappa là 0,8 (1968), 0,76 (1995), 0,78 (2000), 0,79 (2005), 0,78 (2011), và 0,8 (2016). Kết quả là đã tạo ra lớp phủ/sử dụng đất với độ chính xác cao trong năm mốc thời gian để phân tích mở rộng đô thị ởQuần thể di tích Huế.

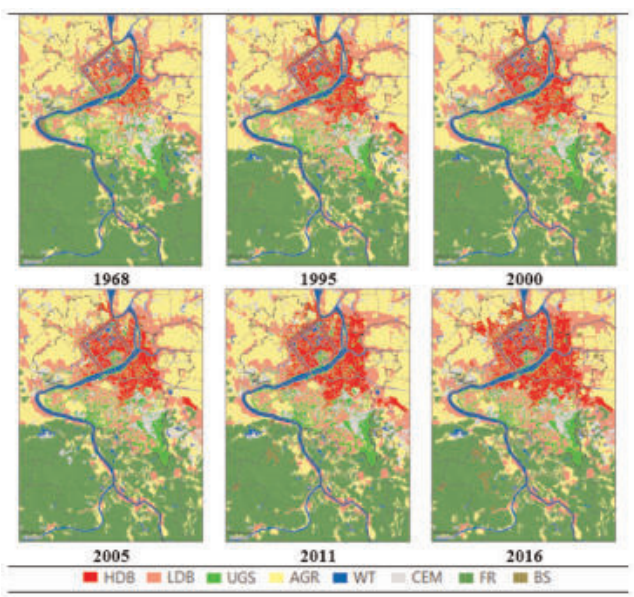

Hình 2: Kết quả phân loại các lớp phủ/sủ dụng đầt giai đoạn 1968-2018.

\section{2. Định hướng không gian và động lục mở rộng đô thị}

Quá trình đô thị hóa ở khu vực Quần thể di tích Huế đã tăng mạnh mẽ kể từ chính sách cải cách và mở cửa đất nước. Diện tích đất đô thị chiếm 3.488,21 ha và chủ yếu phân bố ở thành phố Huế và một phần ít phân bổ ở thị xã Hương Thủy và huyện Phú Vang năm 1968. Diện tích đô thị tăng 1.035,23 ha từ 3.488,21 ha năm 1968 lên 4.523,44 ha vào năm 1995 và diện tích đất đô thị tiếp tục tăng 119,76 ha vào năm 2000 là 4.643,20 ha. Trong khi đó, là khu vực đô thị không có những giới hạn rạch ròi giữa nội thành và ngoại thành. Bản chất quy hoạch theo hình thái xen kẽ các không gian và các mảng kiến trúc dẫn tới sự hòa tan và sự hòa quyện chúng với nhau, hình thành một hốn hợp kiến trúc đô thị-thôn quê, cảnh quan và cuộc sống dựa vào đất chứ không phải dựa vào phố, là chính. Do đó, đất đô thị không chỉ mở rộng ra phía Đông và phía Nam của khu vực mà còn xuất hiện trong kêt nối giữa thành phố Huế với các khu phát triển xung quanh. Sự phát triển nhanh chóng của việc mở rộng đô thị hóa xảy ra trong giai đoạn 2000- 
2016.Diện tích đất đô thị mở rộng lần lượt lên 295,04 ha vào năm 2005 (4.938,24 ha), 490,96 ha vào năm $2011(5.429,20$ ha) và 592,83 ha vào năm 2016 (6.022,03 ha). Không chỉ có sự khác biệt về tổng diện tích tự nhiên mà diện tích đất đô thị của khu vực Quần thể di tích Huế cũng có sự khác biệt. Từ năm 2005-2016, diện tích đất đô thị tăng nhanh một phần do huyện Hương Thủy và Hương Trà được thành lập là thị xã Hương Thủy và thị xã Hương Trà, diện tích đất đô thị của khu vực đã tăng lên rõ rệt. (Hình 3, bảng 1)

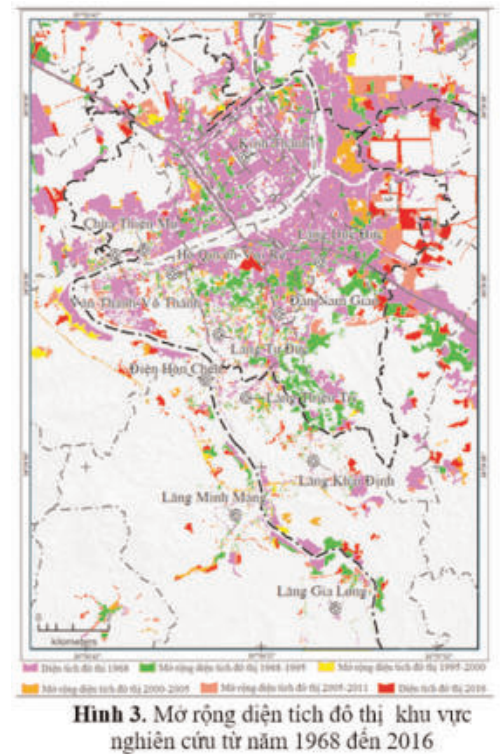

Diện tích đất đô thị của khu vực Quần thể di tích Huế tăng $2.533,81$ ha với diện tích mở rộng hàng năm là 52,79 ha và chỉ số cường độ đô thị hóa là 0,24 trong cả giai đoạn từ 1968-2016. Quá trình đô thị hóa trong giai đoạn nghiên cứu được chia thành năm giai đoạn, đó là giai đoạn đầu (1968-1995); giai đoạn phát triển nhanh chóng (1995-2000); giai đoạn phát triển (2000-2005); giai đoạn phát triển tương đối nhanh (20052011); và cuối cùng là giai đoạn phát triển nhanh (2011-2016). (Xem hìn 4)

Tốc độ mở rộng đô thị hóa là 38,34 ha/năm và có khoảng 1.035,23 ha được chuyển đổi thành đất đô thị trong giai đoạn 1968-1995. Tỷ lệ mở rộng đô thị $(23,95 \mathrm{ha} /$ năm) trong năm năm tiếp theo của giai đoạn 1995-2000 thấp hơn so với giai đoạn đầu. Từ năm 2000, việc mở rộng đất đô thị bắt đầu phát triển với tốc độ mở rộng 59,01 ha/năm, gấp hơn hai lần so với giai đoạn 1995 2000, do sự phát triển kinh tế nhanh chóng và sự gia tăng dân số nhanh trong giai đoạn này. Diên tích mở rộng đô thị đạt tới 490,96ha, 592,82ha trong các giai đoạn tiếp theo 2005-2011 và 20112016 trong vòng 11 năm, và các giá trị của chỉ số cường độ đô thị hóa lần lượt là 0,$17 ; 0,11 ; 0,26$; 0,36 ; và 0,53 trong các giai đoạn 1968-1995; $1995-2000$; 2000-2005; 2005-2011; và 20112016 (Bảng 1). Giá trị cao của chỉ số cường độ đô thị hóa trong 2011-2016 cho thấy sự mở rộng diện tích đất đô thị rất lớn trong giai đoạn này. Sự mở rộng đô thị hóa và thay đổi mô hình cảnh quan được xác định bởi nhiều yếu tố, chẳng hạn như vị trí địa lý, dân số, chính sách kinh tế, tài nguyên và cơ sở hạ tầng giao thông hiện đại. Những lợi thế từ vị trí là đô thị trung tâm của tỉnh Thừa Thiên Huế, nằm tại miền Trung Việt Nam, trên các trục đường giao thông quan trọng nối hai miền NamBắc của Việt Nam như đường quốc lộ, đường sắt Bắc Nam. Sự phân bố không gian của đất đô thị mở rộng theo nhiều hướng tại khu vực Quần thể di tíchHuế trong những thập kỷ qua, trong đó phía Đông Nam cho thấy xu hướng mở rộng đáng kể nhất (Hình 4).

\subsection{Phân tích mở rộng diện tích đô thị bằng chỉ số đô thị hóa tại 12 di tích thuộc Quần thể di tích Huế theo khoanh vùng bảo vệ}

Các mẫu dạng không gian của ba chỉ số mô tả quá trình đô thị hóa được thể hiện Hình5. Chỉ số Tăng hàng năm (AI) tương đối lớn trong khu vực di tích ở phía nam thành phố Huế, phía tây thị xã Hương Thủy và phía đông thị xã Hương Trà (Hình 5-bên trái), nơi có nhiều di tích bao gồm Lăng Gia Long, Lăng Minh Mạng, Lăng Khải Định, Lăng Thiệu Trị, và Điện Hòn Chén. Cụ thể, trong khu vực vùng đệm, cường độ mở rộng hàng năm theo quan sát: Lăng Thiệu Trị (168,9\%), Điện Hòn Chén $(137,5 \%)$, Văn Thánh-Võ Thánh (136,59\%), và Lăng Khải Định $(100 \%)$. Trong khi đó, đối với vùng bảo vệ cảnh quan (BVCQ), Lăng Gia Long (332,62\%), Lăng Khải Định $(267,71 \%)$, Chùa Thiên Mụ (192,29\%), Lăng Minh Mạng (162,8\%), Lăng Thiệu Trị $(150,39 \%)$, và Lăng Tự Đức (128,59\%). (Xem hìn 5)

Tại trung tâm thành phố Huế, quá trình đô thị hóa cũng diê̂n ra, như ở xung quanh Đàn Nam Giao, Lăng Tự Đức. Tuy nhiên, khu vực di tích ở phía tây thành phố Huế (Chùa Thiên Mụ, Văn 
Bảng 1: Mở rộng đô thị hóa ở khu vục Quần thể di tích Huế trong các giai đoạn lịch sử

\begin{tabular}{|c|c|c|c|}
\hline Giai đoạn & $\begin{array}{c}\text { Diện tích mở rộng } \\
\text { (ha) }\end{array}$ & $\begin{array}{c}\text { Diện tích mở rộng } \\
\text { hàng năm (ha/năm) }\end{array}$ & Cường độ đô thị hóa \\
\hline $1968-1995$ & $1.035,23$ & 38,34 & 0,17 \\
\hline $1995-2000$ & 119,76 & 23,95 & 0,11 \\
\hline $2000-2005$ & 295,04 & 59,01 & 0,26 \\
\hline $2005-2011$ & 490,96 & 81,83 & 0,36 \\
\hline $2011-2016$ & 592,82 & 118,56 & 0,53 \\
\hline $\mathbf{1 9 6 8 - 2 0 1 6}$ & $\mathbf{2 . 5 3 3 , 8 1}$ & $\mathbf{5 2 , 7 9}$ & $\mathbf{0 , 2 4}$ \\
\hline & & & \\
& & & \\
& &
\end{tabular}

Hình 4: Định hướng không gian mở rộng đô thị ở khu vực Quần thể di tích Huế tù̀ năm 1968 đến 2016 (bên trái), và định hương không gian mở rộng đất đô thị theo quy hoạch 2020 (bên phải)

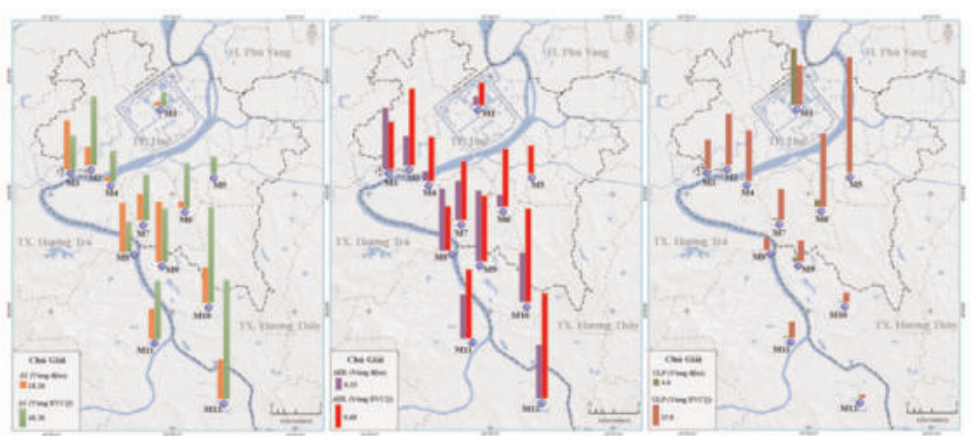

Hình 5: Chỉ số Tăng hàng năm (AI \%) - Bên trái; Chỉ số Mở rộng hàng năm (AER\%) - Giũa; và Chỉ số phần trăm đất đô thị (ULP\%) - Bên phải

Thánh-Võ Thánh, Hổ Quyền-Voi Ré) cho thấy sự thay đổi vừa phải. Cũng quan sát thấy kết quả tương tự đối với chỉ số mở rộng hàng năm(AER) (Hình 5-ở giữa). Giá trị của chỉ số phần trăm đất đô thị (ULP) chỉ ra rằng diện tích đất đô thị lớn hơn ở các di tích Lăng Dục Đức, Đàn Nam Giao, Hổ Quyền-Voi Ré, Chùa Thiên Mụ, và Kinh Thành (là những di tích nằm trong thành phố Huế), ngược lại với diện tích đất đô thị ở các di tích khác, có đặc điểm không gian không đồng nhất về mặt địa lý trong số 12 điểm di tích (Hình 5 - bên phải). (Xem bảng 2)

Bảng 2 mô tả chỉ số hạ tầng xanh đô thị
(UGI) (ha) đối với chín trong số 12 di tích cũng như sự khác biệt về chỉ số UGI theo các năm (\%). Chỉ số UGI được tính dựa trên phân loại lớp phủ/sử dụng đất từ 1968-2016. Hầu hết các di tích đều biểu lộ sự suy giảm rõ rệt chỉ số UGI. Tuy nhiên, có sự biến động lớn giữa các di tích. Ví dụ như: Kinh Thành (M1) có chỉ số UGI giảm lớn nhất $(-60,42 \%$ ở vùng đệm, $-44,49 \%$ ở vùng BVCQ) trong gần 5 thập kỷ, với diện tích đất đô thị (40,81\% vùng đệm, 28,71\% vùng BVCQ). Giá trị UGI cũng giảm đáng kể ở Lăng Dục Đức (-82,17\%), Lăng Tự Đức (-47,32\% ở vùng đệm và $-63,70 \%$ ở vùng $\mathrm{BVCQ})$ trong đó đất đô thị 
lần lượt chiếm $82,7 \%$ và $35 \%$ (vùng đêm và vùng $\mathrm{BVCQ}$ ). Đối với đàn Nam Giao, chỉ số UGI giảm $(-52,13 \%$ vùng đệm và $-68,18 \%$ vùng BVCQ) trong đó diện tích đất đô thị chiếm $56,9 \%$ tổng diện tích đất.

Kết quả trên cho thấy một sự tăng lên liên tục diện tích đất đô thị được quan sát mỗi giai đoạn cho tất cả các di tích. Đất đô thị tăng lên 121\% trong vòng 27 năm (1968-1995) và $115 \%$ trong 21 năm tiếp theo (1995-2016). Tổng diện tích đất đô thị tăng là 236\% từ 1968-2016. Tỷ lệ mở rộng đô thị nhanh hơn một chút ở giai đoạn 1995-2016 so với giai đoạ 1968-1995. Sự phát triển đất đô thị tại 12 di tích cũng thấy rõ nhưng ở tốc độ chậm hơn đặc biệt từ giai đoạn 19681995. Trong khi đó, quá trình mở rộng đô thị diễn ra mạnh hơn về cả tốc độ lẫn yếu tố không gian giữa giai đoạn 1995-2016 vớigiai đoạn 1968-1995. Có thể thấy diện tích đất đô thị tăng nhẹ trong 48 năm ở 12 di tích, tương ứng với mức mở rộng 39\% so với phạm vi ban đầu của các di tích.Chỉ số thực thể xanh (UGS) cao ở một số di tích như Lăng Tự Đức góp phần làm cải thiện cảnh quan di tích hòa nhập với khung cảnh tự nhiên xung quanh. Cần lưu ý là nhà Nguyễn xây dựng kinh đô Huế và các di tích có cân nhắc kỹ yếu tố cây xanh và không gian xanh để phục vụ nhu cầu trang trí cảnh quan, làm cho các khối công trình xây dựng to lớn trở nên hài hòa với thiên nhiên, sông suối và cảnh quan nói chung. Ngược lại, quá trình đô thị hóa lộn xộn đương đại đã làm mất cân bằng và ảnh hưởng tiêu cực đến sự phát triển bền vững của thành phố Huế.

\section{Kết luận}

Nghiên cứu này đã chứng minh việc sử dụng tiềm năng của phân tích lớp phủ/sử dụng đất và chỉ số đô thị hóa trong việc tìm hiểu động lực không gian mở rộng đô thị trong một đô thị phát triển nhanh chóng như Quần thể di tích Huế dựa trên dữ liệu viễn thám đa thời gian. Các số liệu mở rộng đô thị được sử dụng trong nghiên cứu này như Tỷ lệ mở rộng đô thị hàng năm (AER), chỉ số Tăng hàng năm $(\mathrm{AI})$, chỉ số phần trăm đât đô thị (ULP), và chỉ số hạ tầng xanh đô thị (UGI) là nhưng công cụ rất phù hợp để hiểu các quá trình liên quan đến tăng trưởng thành của khu vực nghiên cứu. Trên cơ sở sử dụng dữ liệu ảnh vệ tinh đa thời gian và các chỉ số đô thị hóa, quá trình mở rộng diện tích đô thị diễn ra ở trong tất cả các giai đoạn. Điển hình nhất là giai đoạn (1968-1995) và giai đoạn (1995-2016) với mức tăng lên tới $121 \%$ và $115 \%$. Điều này không chỉ gây ra tình trạng thu hẹp diện tích Đất nông nghiệp $(\mathrm{AGR})$ và Đất rừng $(\mathrm{FR})$, mà còn hình

\section{Bảng 2: Chỉ số Cơ sở hạ tầng xanh đô thị (UGI) tại chín di tích: Kinh Thành (M1), Chùa Thiên} Mu (M2), Văn Thánh-Võ Thánh (M3), Hổ Quyền-Voi Ré (M4), Lăng Dục Đức (M5),

Đàn Nam Giao (M6), Lăng Tụ Đức (M7), Điện Hòn Chén (M8), Lăng Thiệu Trị (M9)

\begin{tabular}{|c|c|c|c|c|c|c|c|c|c|c|c|c|c|c|c|c|c|}
\hline \multirow{2}{*}{$\begin{array}{l}\text { CGI } \\
1968\end{array}$} & \multicolumn{2}{|c|}{ Diện tich (ha) } & \multirow{2}{*}{$\begin{array}{l}\text { UGI } \\
1995\end{array}$} & \multicolumn{2}{|c|}{ Diện tich (ha) } & \multirow{2}{*}{$\begin{array}{l}\text { UGI } \\
2000\end{array}$} & \multicolumn{2}{|c|}{ Diện tích (ha) } & \multirow{2}{*}{$\begin{array}{c}\text { UGI } \\
2005\end{array}$} & \multicolumn{2}{|c|}{ Diện tich (ha) } & \multirow{2}{*}{$\begin{array}{l}\text { UGI } \\
2011\end{array}$} & \multicolumn{2}{|c|}{ Diện tích (ha) } & \multirow{2}{*}{$\begin{array}{l}\text { UGI } \\
2016\end{array}$} & \multicolumn{2}{|c|}{ Diện tích (ha) } \\
\hline & $\begin{array}{l}\text { Vùng } \\
\text { dẹm }\end{array}$ & $\begin{array}{l}\text { Vuing } \\
\text { BVCQ }\end{array}$ & & $\begin{array}{l}\text { Vùng } \\
\text { đẹm }\end{array}$ & $\begin{array}{l}\text { Vung } \\
\text { BVCQ }\end{array}$ & & $\begin{array}{l}\text { Vùng } \\
\text { đẹm }\end{array}$ & $\begin{array}{l}\text { Vung } \\
\text { BVCQ }\end{array}$ & & $\begin{array}{l}\text { Vùng } \\
\text { đẹmm }\end{array}$ & $\begin{array}{l}\text { Vùng } \\
\text { BVCQ }\end{array}$ & & $\begin{array}{l}\text { Vüng } \\
\text { sẹmm }\end{array}$ & $\begin{array}{l}\text { Vùng } \\
\text { BVCQ }\end{array}$ & & $\begin{array}{l}\text { Vüng } \\
\text { defm }\end{array}$ & $\begin{array}{l}\text { Vùng } \\
\text { BVCQ }\end{array}$ \\
\hline In & 0.12 & 0.35 & n & 0.07 & 0.24 & Mn & 0.07 & 0.25 & MII & 0.07 & 0.24 & MI & 0.05 & 0.20 & Mn & 0.05 & 0.19 \\
\hline ME3 & 5.29 & 2.39 & M3 & 4.71 & 1.77 & MI3 & 3.61 & 1.58 & M3 & 2.27 & 1.47 & M3 & 1.21 & 1.08 & $\mathrm{M} 3$ & 0.65 & 0.74 \\
\hline $\mathrm{MI} 4$ & 1.05 & 1.93 & $\mathrm{M} 4$ & 1.04 & 1.23 & $\mathrm{MI} 4$ & 0.94 & 1.08 & $\mathrm{M} 4$ & 0.91 & 1.01 & $\mathrm{M} 4$ & 0.89 & 0.92 & $\mathrm{M} 4$ & 0.82 & 2.84 \\
\hline M5 & . & 0.43 & M5 & 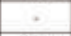 & 0.13 & MI5 & - & 0.12 & M5 & 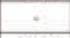 & 0.10 & M15 & 0.00 & 0.09 & M5 & 0.00 & 0.08 \\
\hline M7 & 6.93 & 6.44 & M7 & 4.59 & 3.33 & MI7 & 4.59 & 3.20 & M7 & 4.19 & 2.95 & $\mathbf{M} 7$ & 3.92 & 2.62 & M7 & 3.65 & 2.34 \\
\hline Ms & - & 0.54 & MS & - & 0.38 & Ms & - & 0.37 & Ms & + & 0.35 & MIs & - & 0.33 & IS & - & 0.28 \\
\hline M9 & - & 1.25 & & - & 0.68 & & - & 0.63 & & - & 0.00 & & 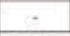 & 0.50 & & 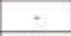 & 0.49 \\
\hline \multirow{2}{*}{$\begin{array}{l}\text { (1968- } \\
\text { 1995) }\end{array}$} & \multicolumn{2}{|c|}{ Phà̀n tràm (\%) } & \multirow{2}{*}{$\begin{array}{l}\text { (1995- } \\
\text { 2000) }\end{array}$} & \multicolumn{2}{|c|}{ Phần tràm (\%) } & \multirow[b]{2}{*}{$\begin{array}{l}(2000- \\
2005)\end{array}$} & \multicolumn{2}{|c|}{ Phần tràm $(\%)$} & \multirow{2}{*}{$\begin{array}{l}\text { (2005- } \\
2011)\end{array}$} & \multicolumn{2}{|c|}{ Phần tràm $(\%)$} & \multirow[b]{2}{*}{$\begin{array}{l}\text { (2011- } \\
\text { 2016) }\end{array}$} & \multicolumn{2}{|c|}{ Phần trám (\%) } & \multirow[b]{2}{*}{$\begin{array}{l}\text { (1968- } \\
\text { 2016) }\end{array}$} & \multicolumn{2}{|c|}{ Phần tràm $(\%)$} \\
\hline & $\begin{array}{l}\text { Vùng } \\
\text { đềm }\end{array}$ & $\begin{array}{l}\text { Vùng } \\
\text { BVCQ }\end{array}$ & & $\begin{array}{l}\text { Vùng } \\
\text { đêm }\end{array}$ & $\begin{array}{l}\text { Vung } \\
\text { BVCQ }\end{array}$ & & $\begin{array}{l}\text { Vung } \\
\text { đecm }\end{array}$ & $\begin{array}{l}\text { Vung } \\
\text { BVCQ }\end{array}$ & & $\begin{array}{l}\text { Vùng } \\
\text { đẹmm }\end{array}$ & $\begin{array}{l}\text { Vùng } \\
\text { BVCQ }\end{array}$ & & $\begin{array}{l}\text { Vùng } \\
\text { dèm }\end{array}$ & $\begin{array}{l}\text { Vuing } \\
\text { BVCQ }\end{array}$ & & $\begin{array}{l}\text { Vùng } \\
\text { dêm }\end{array}$ & $\begin{array}{l}\text { Vùng } \\
\text { BVCQ }\end{array}$ \\
\hline M4 & -1.45 & -36.52 & MI4 & -9.36 & -11.68 & $\mathrm{M} 4$ & -2.70 & -6.86 & $\mathrm{M} 4$ & -2.63 & -9.22 & $\mathrm{M} 4$ & -7.88 & -8.56 & $\mathrm{M} 4$ & -22.04 & -56.66 \\
\hline M5 & - & .70 .26 & M15 & $\cdot$ & -9.23 & M5 & - & -13.70 & M5 & - & -11.62 & M5 & $\cdot$ & -13.39 & M5 & 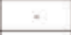 & -82.17 \\
\hline M6 & -39.64 & -37.49 & M6 & -0.66 & -6.84 & M6 & -11.45 & -20.13 & MI6 & -0.13 & -11.64 & M6 & .9 .73 & -22.57 & M6 & -52.13 & .68 .18 \\
\hline M7 & -33.83 & -48.28 & 317 & - & -4.10 & M7 7 & -8.59 & -7.65 & M7 & -6.47 & -11.16 & M7 7 & -6.89 & -10.80 & M7 & -47.32 & -63.70 \\
\hline IIS & $\cdot$ & -30.60 & Ms & - & -2.61 & MIS & - & -3.61 & MS & 2 & -6.32 & MS & 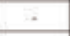 & -14.79 & Ms & - & -48.00 \\
\hline MI9 & -44.03 & -45.17 & M9 & -4.75 & -6.74 & $\mathrm{MI9}$ & -17.97 & -11.19 & M9 & -13.49 & $-11,15$ & M9 & -1.73 & -1.74 & M9 & -62.82 & -60.36 \\
\hline
\end{tabular}


thành nguy cơ tác động đến môi trường (chức năng sinh thái) của lãnh thổ.Hiểu các qua trình tăng trưởng đô thị và xác định các quá trình này ở quy mô của đơn vị hành chính là điều cần thiết để quản lý và lập kế hoạch cho các quá trình đô thị hóa. Kết quả đã chỉ ra rằng tốc độ và mô hình mở rộng đô thị khác nhau trong khu vực nghiên cứu cả về không gian và thời gian. Tuy nhiên, các nghiên cứu trong tương lai cần tập trung vào việc xác định các yếu tố thúc đẩy mở rộng đô thị trong khu vực Quần thể di tích Huế và sự không đồng nhất về không gian để hiểu hơn về quá trình đô thị hóa để đảm bảo quy hoạch hiệu quả của khu vực nghiên cứu. $\bigcirc$

\section{Tài liệu tham khảo}

[1]. A.Agapiou, D.G. Hadjimitsis, Vegetation indices and field spectro-radiometric measurements for validation of buried architectural remains Verification under area surveyed with geophysical campaigns, J. Appl. Remote Sens. 5 (2011), http://dx.doi.org/10.1117/1.3645590.

[2]. Doxa A., C.H. Albert, A. Leriche, A. Saatkamp (2017). Prioritizing conservation areas for coastal plant diversity under increasing urbanization, Journal of Environmental Management, Volume 201, 425-434.

[3]. Erener, A., 2013. Classification method, spectral diversity, band combination and accuracy assessment evaluation for urban feature detection. Int. J. Appl. Earth Obs. Geoinformation 21, 397-408. https://doi.org/10.1016/j.jag.2011.12.008.

[4]. G., \& Kumar, S. (2011). Forecasting urban growth based on GIS, RS and SLEUTH model in Pune metropolitan area. International Journal of Geomatics and Geosciences, 2(2), 568-579.

[5]. Geymen, A., \& Baz, I. (2008). Monitoring urban growth and detecting landcover changes on the Istanbul metropolitan area. Environmental Monitoring and Assessment, 136(1e3), $449 \mathrm{e} 459$. http://doi.org/10.1007/s10661-007-9699-x.

[6]. Guetté A., P. Gaüzère, V. Devictor, F. Jiguet, L. Godet (2017). Measuring the synanthropy of species and communities to monitor the effects of urbanization on biodiversity,
Ecological Indicators, Volume 79, 139-154.

[7]. Haas J., D. Furberg, Y. Ban (2015) Satellite monitoring of urbanization and environmental impacts-A comparison of Stockholm and Shanghai, International Journal of Applied Earth Observation and Geoinformation 38, 138-149.

[8]. Liu Y., X. Huang, H. Yang, T. Zhong (2014) Environmental effects of land-use/cover change caused by urbanization and policies in Southwest China Karst area - A case study of Guiyang, Habitat International 44, 339-348

[9]. Lopez R.D., R.C. Frohn (2018) Remote sensing for landscape ecology: monitoring, modeling, and assessment of ecosystems, CRC Press, 286 pages.

[10]. Richter, R., Schläpfer, D., \& Müller, A. (2006). An automatic atmospheric correction algorithm for visible/NIR imagery. International Journal of Remote Sensing, 27(10), 2077-2085. doi: $10.1080 / 01431160500486690$.

[11]. S. W. Myint, P. Gober, A. Brazel, S. Grossman-Clarke, and Q. Weng, "Per-pixel vs. object-based classification of urban land cover extraction using high spatial resolution imagery," Remote Sens. Environ., vol. 115, no. 5, pp. 1145-1161, May 2011.

[12]. Shrestha M.K., A.M. York, C.G. Boone, S. Zhang (2012) Land fragmentation due to rapid urbanization in the Phoenix Metropolitan Area: Analyzing the spatiotemporal patterns and drivers, Applied Geography, Volume 32, Issue 2, 522-531.

[13]. X. Niu and Y. Ban, "Multi-temporal RADARSAT-2 polarimetric SAR data for urban land-cover classification using an object-based support vector machine and a rule-based approach," Int. J. Remote Sens., vol. 34, no. 1, pp. 1-26, Jan. 2013.

[14]. Xu Q., Y. Dong, R. Yang (2018) Urbanization impact on carbon emissions in the Pearl River Delta region: Kuznets curve relationships, Journal of Cleaner Production, Volume 180, 514-523.

(Xem tiếp trang 49) 